\title{
Physical Performance and Frailty in Chronic Kidney Disease
}

\author{
Peter P. Reese ${ }^{a-c}$ Anne R. Cappolad Justine Shults ${ }^{\text {b, e }}$ Raymond R. Townsend ${ }^{a}$ \\ Crystal A. Gadegbeku ${ }^{f}$ Cheryl Andersong ${ }^{\text {Joshua F. Baker }}{ }^{\text {h }}$ Dean Carlow $^{\text {e }}$

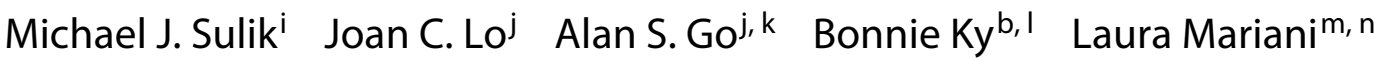 \\ Harold I. Feldman ${ }^{a-c}$ Mary B. Leonard ${ }^{b, e}$ CRIC Study Investigators
}

\begin{abstract}
${ }^{a}$ Renal Division, Department of Medicine, ${ }^{b}$ Department of Biostatistics and Epidemiology, Perelman School of Medicine at the University of Pennsylvania, 'Leonard Davis Institute of Health Economics, University of Pennsylvania, ${ }^{d}$ Division of Endocrinology, Diabetes, and Metabolism, Department of Medicine, Perelman School of Medicine at the University of Pennsylvania, ${ }^{\mathrm{e} T h e}$ Children's Hospital of Philadelphia, and 'Section of Nephrology, Temple University School of Medicine, Philadelphia, Pa., ${ }^{9}$ Department of Family and Preventive Medicine, University of California San Diego, La Jolla, Calif., h Rheumatology Division, Department of Medicine, Perelman School of Medicine at the University of Pennsylvania, Philadelphia, Pa., 'Department of Psychology, Arizona State University, Phoenix, Ariz., jDivision of Research, Kaiser Permanente Northern California, Oakland, Calif., ${ }^{k}$ Department of Health Research and Policy, Stanford University School of Medicine, Palo Alto, Calif., 'Cardiology Division, Department of Medicine, Perelman School of Medicine at the University of Pennsylvania, Philadelphia, Pa., ${ }^{m}$ Renal Division, University of Michigan Medical School, and ${ }^{n}$ Arbor Research Collaborative for Health, Ann Arbor, Mich., USA
\end{abstract}

\section{Key Words}

Physical performance $\cdot$ Frailty $\cdot$ Chronic kidney disease

\begin{abstract}
Background: Poor physical performance and frailty are associated with elevated risks of death and disability. Chronic kidney disease (CKD) is also strongly associated with these outcomes. The risks of poor physical performance and frailty among CKD patients, however, are not well established. Methods: We measured the Short Physical Performance Battery (SPPB; a summary test of gait speed, chair raises and balance; range 0-12) and the five elements of frailty among 1,111 Chronic Renal Insufficiency Cohort participants. Adjusting for demographics and multiple comorbidities, we fit a linear regression model for the outcome of SPPB score and an ordinal logistic regression model for frailty status.
\end{abstract}

Results: Median (interquartile range, IQR) age was 65 (5771) years, median estimated glomerular filtration rate (eGFR) for non-dialysis patients was $49(36-62) \mathrm{ml} / \mathrm{min} / 1.73 \mathrm{~m}^{2}$, and median SPPB score was 9 (7-10). Seven percent of participants were frail and $43 \%$ were pre-frail. Compared with the SPPB score for eGFR $>60 \mathrm{ml} / \mathrm{min} / 1.73 \mathrm{~m}^{2}$, the SPPB was 0.51 points lower for eGFR 30-59; 0.61 points lower for eGFR 1529 , and 1.75 points lower for eGFR $<15$ ( $p<0.01$ for all comparisons). eGFR 30-59 (odds ratio, OR 1.45; $\mathrm{p}=0.024$ ), eGFR 15-29 (OR 2.02; $p=0.002$ ) and eGFR <15 (OR 4.83; $p<0.001$ ) were associated with worse frailty status compared with eGFR $>60 \mathrm{ml} / \mathrm{min} / 1.73 \mathrm{~m}^{2}$. Conclusions: CKD severity was

CRIC Investigators: Lawrence J. Appel, Harold I. Feldman, Alan S. Go, Jiang He, John W. Kusek, James P. Lash, Akinlolu Ojo, Mahboob Rahman, Raymond R. Townsend.

\section{KARGER}

E-Mail karger@karger.com

www.karger.com/ajn
(C) 2013 S. Karger AG, Basel

0250-8095/13/0384-0307\$38.00/0
Peter P. Reese, MD, MSCE

917 Blockley Hall, Department of Biostatistics and Epidemiology

423 Guardian Drive, University of Pennsylvania

Philadelphia, PA 19104 (USA)

E-Mail peter.reese@uphs.upenn.edu 
associated with poor physical performance and frailty in a graded fashion. Future trials should determine if outcomes for CKD patients with frailty and poor physical performance are improved by targeted interventions.

(c) 2013 S. Karger AG, Basel

\section{Introduction}

Chronic kidney disease (CKD) is associated with elevated risks of disability, hospitalization and death [1-3]. These adverse outcomes may be due to systemic inflammation, cachexia and the high prevalence of cardiovascular disease (CVD) and endocrinopathies such as diabetes mellitus in CKD [4-7]. Measures of physical performance and frailty, initially validated in elderly populations, reveal a loss of physiologic reserve and susceptibility to functional decline [8-10]. However, the prevalence and determinants of poor physical performance and frailty have not been well described in a population with a wide spectrum of renal dysfunction and a broad age range. Poor physical performance and frailty could lie in the pathway between CKD and adverse health outcomes and deserve closer scrutiny.

Compared to self-reported measures of function, physical performance tests such as the Short Physical Performance Battery (SPPB) provide objective measurements that are readily compared across populations $[10$, 11]. These measures serve as powerful independent predictors of disability, hip fracture, hospitalization, and mortality in the elderly $[12,13]$, and can identify meaningful differences in function even among individuals without any known disability [10].

Frailty is a clinical syndrome of global loss of resilience and diminished capacity to respond to health stressors [9]. Limited data exist about predictors and consequences of frailty in patients with chronic renal insufficiency [14] Among elderly ( $>65$ years) community-dwelling individuals in the Cardiovascular Health Study (CHS), mild to moderate elevation in serum creatinine was associated with a greater prevalence of frailty [15]. Using a modified frailty measure derived from questionnaires, Johansen and colleagues applied the frailty construct to dialysis populations in two studies that had similar findings $[16,17]$. In a study of 2,275 incident dialysis patients in the Dialysis Morbidity and Mortality Wave 2 cohort, Johansen's group found that two thirds were identified as frail. Independent of age, comorbidities and laboratory measures collected during dialysis, frailty was associated with hospitalization and death [16]. Roshanravan et al. [18] assessed frailty among 336 middle-aged patients with CKD in the Seattle Kidney Study and found a strong association between frailty and a combined outcome of death and/or dialysis.

The aims of this cross-sectional study were to (1) determine if greater CKD severity was independently associated with the end points of poor physical performance and frailty in a large, racially diverse sample of adults with $\mathrm{CKD}$, and (2) identify additional risk factors for poor physical performance and frailty in CKD.

\section{Methods}

\section{Study Population}

The Chronic Renal Insufficiency Cohort (CRIC) is a multicenter prospective study of progression of renal disease, risk factors for CVD, and mortality in 3,939 adults. Inclusion criteria included ages 21-74 years with an estimated glomerular filtration rate (eGFR) between 20 and $70 \mathrm{ml} / \mathrm{min} / 1.73 \mathrm{~m}^{2}$ at enrollment. Exclusions included institutionalization or severe comorbidities such as stage III-IV congestive heart failure (CHF). Sociodemographic characteristics, medical conditions and medications were self-reported at baseline and updated annually. Body mass index (BMI) was measured annually $[19,20]$.

After institutional review board approval, this cross-sectional Physical Performance Ancillary Study was conducted at four of the seven CRIC centers from April 2008 to February 2010. Participants who had not received a kidney transplant were eligible. Participants provided informed consent [19-21].

\section{Primary Exposure}

The primary exposure was eGFR calculated using the CRIC equation [22] and was categorized as $\geq 60,30-59,15-29$, or $<15 \mathrm{ml} /$ $\mathrm{min} / 1.73 \mathrm{~m}^{2}$ (the $<15 \mathrm{ml} / \mathrm{min} / 1.73 \mathrm{~m}^{2}$ category included participants receiving chronic dialysis).

\section{Outcomes}

The outcomes were SPPB score and frailty status. The SPPB score (range 0-12) was derived from (1) the faster of two timed, usual pace, 15 -foot walks, (2) tests of standing balance in the sideby-side, semi-tandem and tandem positions, and (3) a timed series of five attempts to stand from a chair with arms crossed on the chest [11]. For each component, a five-level categorical score was assigned, with 0 representing inability to attempt or complete the test and 4 representing the highest level of performance $[10,11,23$, 24].

Frailty status was defined using five criteria, as described by Fried: slow gait speed, muscle weakness, low physical activity, exhaustion and unintentional weight loss $[9,13]$. Gait was assessed with the timed walk used in the SPPB. Exhaustion was assessed using two questions from the Center for Epidemiologic Studies Depression scale (CES-D) [25]. Muscle weakness was determined using the average of three grip strength tests using a Digital Grip Dynamometer (Creative Health Products, Ann Arbor, Mich., USA). The weight loss criterion was satisfied if change in weight between the visit one year earlier and the current visit revealed $\geq 5 \%$ loss and the participant denied intentional weight loss. For low physical activity, energy expenditure was assessed using the 
Multi-Ethnic Study of Atherosclerosis Physical Activity Questionnaire [26]. Similar to the approaches used by other studies of frailty, we used items related to household and outdoor chores, as well as walking and other deliberate exercise activities [9, 13, 27]. We categorized male participants with energy expenditure $<383 \mathrm{kcal} /$ week and female participants with $<270 \mathrm{kcal} /$ week as having low physical activity. Participants who met 3 , 4 , or 5 criteria satisfied the frailty end point, while those who met 1-2 criteria were prefrail and others were non-frail [9].

\section{Exposures}

Covariates included age category $(<50,50-59,60-69$ and $\geq 70$ years), race (black vs. non-black), gender, BMI category $(<25,25-$ $29,30-34, \geq 35$ ), diabetes, anemia, CVD (clinical history of myocardial infarction, coronary revascularization or CHF), stroke, category of highest education (college graduate or higher, some college, high school graduate, less than high school graduation), income (USD >100,000, 50,001-100,000, 20,001-50,000, <20,000), and $25(\mathrm{OH}) \mathrm{D}$ deficiency $(<20 \mathrm{ng} / \mathrm{ml})[28]$.

We also compared the physical component subscore of the Kidney Disease Quality of Life (KDQOL) instrument across groups defined by eGFR category. The KDQOL comprises questions about physical health-related quality of life [29]. However, we did not adjust for the KDQOL in analyses of frailty and the SPPB because this exposure could plausibly fall in the causal pathway between eGFR and these outcomes.

\section{Laboratory Measurements}

At the visit when the SPPB and frailty were assessed, serum specimens were collected. Serum creatinine was measured using standard enzyme-based assays and calibrated to values at the Cleveland Clinic Research Laboratory [30]. An immunonephelometric assay on the Siemens BN II System was used to measure serum cystatin $\mathrm{C}$ [22]. 25(OH) vitamin D concentrations were quantified using high-performance liquid chromatography coupled with tandem mass spectrometry.

\section{Statistical Analysis}

Analyses were completed using Stata MP 12 (Stata Corporation, College Station, Tex., USA). Continuous variables were reported as median and IQR, while categorical variables were described by percentages. For continuous variables, we used Student's $t$ test or the rank-sum test to compare two groups, as appropriate. The one-way analysis of variance test was used to compare $>2$ groups. Correlations between two continuous variables were assessed using the Pearson's correlation. Categorical variables were compared between groups using $\chi^{2}$.

Multivariable linear regression was performed to determine associations between eGFR category and the outcome of SPPB score. Based on prior literature $[9,15,16,31-33]$, we adjusted for the potential confounders (listed in the 'Exposures' section), except for the KDQOL. We examined the $\mathrm{R}^{2}$ statistic and the distribution of residual errors to confirm model assumptions. As a secondary analysis, we excluded the $80(7 \%)$ individuals who had a score of zero (i.e. no attempt) in any SPPB component; associations between eGFR and the SPPB were similar and not shown.

Multivariable ordinal logistic regression was used to determine the odds ratio (OR) associated with frailty status and eGFR category. The proportional odds assumption was not violated. To avoid overfitting in the context of a limited number of participants with frailty $(\mathrm{n}=73)$, we only added demographics and comorbidities as independent variables to this regression [34]. Additionally, we found nonlinear univariate associations between frailty status and the exposures of age and BMI; large increases in frailty prevalence were evident among participants with age $>65$ years and BMI $>35$. Therefore, we entered age ( $\geq 65$ vs. $<65$ years) and BMI as binary variables $(\geq 35$ vs. $<35)$ in the model.

To confirm the robustness of the results, we fit a logistic regression model for frailty alone. The Hosmer-Lemeshow goodness of fit test showed good calibration $(\mathrm{p}=0.41)$.

To estimate age-adjusted renal function for individuals within each category of frailty status, we fit a linear regression model for the outcome of eGFR and entered age as an independent variable. eGFR was calculated using the CRIC equation [22], and individuals on dialysis were assigned an eGFR of $10 \mathrm{ml} / \mathrm{min} / 1.73 \mathrm{~m}^{2}$. The 'margins' command in Stata was used to derive eGFR from this model.

Guided by the literature suggesting that the impact of black race on mortality for individuals with renal disease differs by age [35, 36], we fit multivariable models for the outcomes of SPPB score and frailty status with interaction terms constructed as the product of black race and age $\geq 65$ years.

\section{Results}

Among 1,344 eligible individuals completing CRIC visits over the study interval at participating sites, 209 (16\%) did not participate in the ancillary, while $24(2 \%)$ individuals not receiving dialysis were excluded due to insufficient laboratory data to calculate eGFR with the CRIC equation. The final analytic sample comprises the remaining $1,111(83 \%)$ participants.

Non-participants and participants in the CRIC ancillary were similar in terms of age $(p=0.39)$ and gender $(\mathrm{p}=0.29)$. However, compared with participants, nonparticipants were more likely to be black (46 vs. $36 \%$; $\mathrm{p}=$ 0.005 ), to have diabetes ( 55 vs. $43 \%$; $\mathrm{p}=0.001$ ), to be on dialysis ( 9 vs. $4 \%$; $\mathrm{p}=0.001$ ) and had lower physical component summary scores of the KDQOL instrument (median 39 vs. 45; $\mathrm{p}<0.001)$.

Table 1 shows participant characteristics. The median age was 65 years (range 24-80, IQR 57-71, mean 63 years). Forty-one participants were on dialysis. The median eGFR among non-dialysis patients was $49 \mathrm{ml} /$ $\mathrm{min} / 1.73 \mathrm{~m}^{2}$ (range 7-146, IQR 36-62). The proportions of participants who were black, had diabetes, or had experienced a stroke or CVD were greater in participants with lower eGFR.

\section{The Short Physical Performance Battery}

Figure 1 shows the distribution of SPPB scores. The mean score was 8.3 (SD 2.4) and the median was 9 (IQR $7-10)$. Nineteen percent had an SPPB score $<7,47 \%$ SPPB 
Table 1. Participant characteristics, overall and according to eGFR category

\begin{tabular}{|c|c|c|c|c|c|c|}
\hline & Overall & $\mathrm{eGFR} \geq 60$ & eGFR 30-59 & eGFR 15-29 & eGFR $<15$ & $\mathrm{p}$ value \\
\hline Patients & 1,111 & 300 & 603 & 148 & 60 & \\
\hline Age, years & $65(57-71)$ & $61(51-66)$ & $67(60-72)$ & $67(60-73)$ & $59(54-67)$ & $<0.001$ \\
\hline Female & $526(47)$ & $143(48)$ & $290(48)$ & $66(45)$ & $27(45)$ & 0.87 \\
\hline Black race & $396(36)$ & $81(27)$ & $217(36)$ & $62(42)$ & $36(60)$ & $<0.001$ \\
\hline Diabetes & $473(43)$ & $82(27)$ & $275(46)$ & $73(49)$ & $43(72)$ & $<0.001$ \\
\hline Anemia & $413(37)$ & $49(16)$ & $224(37)$ & $100(68)$ & $40(68)$ & $<0.001$ \\
\hline $\mathrm{BMI}, \mathrm{kg} / \mathrm{m}^{2}$ & $30(26-35)$ & $29(25-33)$ & $31(26-35)$ & $30(26-35)$ & $31(28-37)$ & $<0.001$ \\
\hline \multicolumn{6}{|l|}{ BMI category } & \multirow[t]{3}{*}{$<0.001$} \\
\hline$<25$ & 204 (19) & $76(25)$ & $89(15)$ & $32(22)$ & $7(12)$ & \\
\hline$\geq 25$ and $<30$ & $353(32)$ & $104(35)$ & $189(32)$ & $39(27)$ & $21(36)$ & \\
\hline \multicolumn{6}{|l|}{ Educational attainment } & \multirow[t]{4}{*}{$<0.001$} \\
\hline High school graduate & $321(29)$ & $65(22)$ & $179(30)$ & $52(35)$ & $25(42)$ & \\
\hline Some college & $158(14)$ & $29(10)$ & $96(16)$ & $28(19)$ & $5(8)$ & \\
\hline College graduate or higher & $81(7)$ & $11(4)$ & $49(8)$ & $12(8)$ & $9(15)$ & \\
\hline \multicolumn{6}{|l|}{ Income stratum in USD } & \multirow[t]{6}{*}{$<0.001$} \\
\hline$<20,000$ & $214(19)$ & $89(30)$ & $101(17)$ & $18(12)$ & $6(10)$ & \\
\hline $20,001-50,000$ & $309(28)$ & $102(34)$ & $155(26)$ & $38(26)$ & $14(23)$ & \\
\hline $50,001-100,000$ & $281(25)$ & $50(17)$ & $169(28)$ & $42(28)$ & $20(33)$ & \\
\hline$>100,000$ & $145(13)$ & $23(8)$ & $89(15)$ & $23(16)$ & $10(17)$ & \\
\hline Declined response & $162(15)$ & $36(12)$ & $89(15)$ & $27(18)$ & $10(17)$ & \\
\hline \multicolumn{7}{|l|}{ KDQOL score } \\
\hline Physical component & $48(37-54)$ & $52(44-55)$ & $48(35-53)$ & $43(33-52)$ & $38(31-47)$ & $<0.001$ \\
\hline Mental component & $55(46-59)$ & $55(46-58)$ & $56(47-59)$ & $55(46-59)$ & $50(42-57)$ & 0.02 \\
\hline
\end{tabular}

Data presented as median (interquartile range) or $\mathrm{n}(\%)$. eGFR calculated using the CRIC eGFR equation. Anemia defined as $<12 \mathrm{~g} / \mathrm{dl}$ for women and $<13 \mathrm{~g} / \mathrm{dl}$ for men. Vitamin D deficiency categorized as $<20 \mathrm{ng} / \mathrm{ml}$.

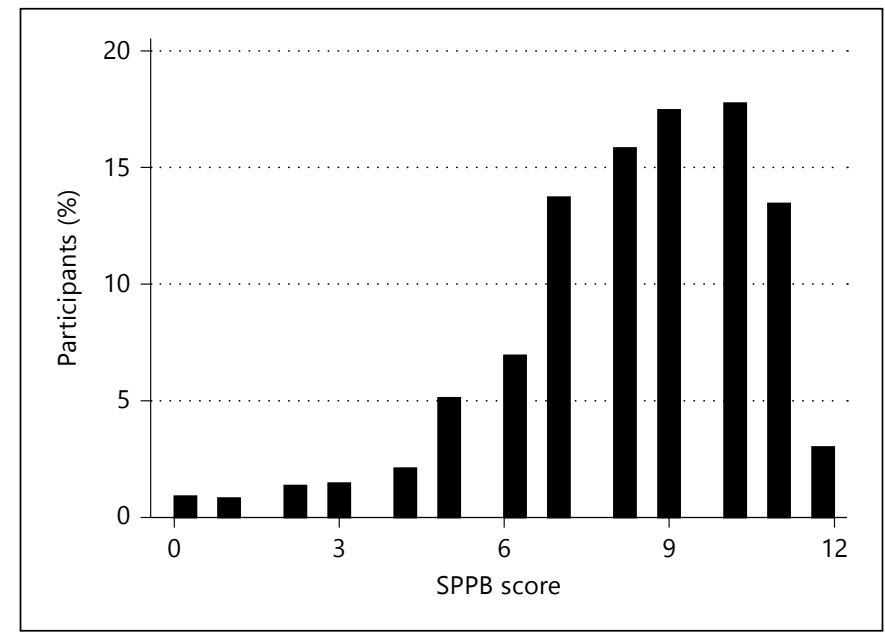

Fig. 1. Distribution of SPPB scores among CRIC participants. $\geq 7$ and $<10$, and $34 \%$ had SPPB $\geq 10$. The SPPB and KDQOL physical component scores were positively associated (rho $=0.49 ; \mathrm{p}<0.001)$.

We observed a graded, independent association between severity of renal dysfunction and worse SPPB score (table 2). In multivariable linear regression, compared with participants with eGFR $>60 \mathrm{ml} / \mathrm{min} / 1.73 \mathrm{~m}^{2}$, eGFR between 30 and 59 was associated with a 0.51 -point lower score, eGFR between 15 and 29 was associated with a 0.61 point lower score, while eGFR $<15$ was associated with a 1.75-point lower SPPB score. Older age, black race, female sex, higher BMI, vitamin D deficiency, a history of stroke or CVD, lower income, and less education were significantly and independently associated with lower SPPB score. Diabetes was not a significant risk factor for lower SPPB score in the full model; however, in a model 
Table 2. Multivariable linear regression model on the outcome of SPPB score

\begin{tabular}{|c|c|c|}
\hline Characteristics & $\beta$-Coefficient (CI) & $\mathrm{p}$ value \\
\hline \multicolumn{3}{|l|}{$\mathrm{eGFR}$ in $\mathrm{ml} / \mathrm{min} / 1.73 \mathrm{~m}^{2}$} \\
\hline$>60$ & reference & \\
\hline$\geq 30$ and $<60$ & $-0.51(-0.80,-0.22)$ & 0.001 \\
\hline$\geq 15$ and $<30$ & $-0.61(-1.03,-0.19)$ & 0.005 \\
\hline$<15$ & $-1.75(-2.33,-1.16)$ & $<0.001$ \\
\hline \multicolumn{3}{|l|}{ Age in years } \\
\hline$<50$ & reference & \\
\hline$\geq 50$ and $<60$ & $-0.36(-0.79,0.08)$ & 0.11 \\
\hline$\geq 60$ and $<70$ & $-0.67(-1.04,-0.29)$ & 0.001 \\
\hline$\geq 70$ & $-1.38(-1.79,-0.97)$ & $<0.001$ \\
\hline Female & $-0.53(-0.78,-0.29)$ & $<0.001$ \\
\hline Black race & $-0.39(-0.68,-0.11)$ & 0.007 \\
\hline Cardiovascular disease & $-0.36(-0.65,-0.08)$ & 0.01 \\
\hline Stroke & $-1.18(-1.60,-0.77)$ & $<0.001$ \\
\hline Diabetes & $-0.24(-0.49,0.02)$ & 0.07 \\
\hline Anemia & $-0.26(-0.53,0.01)$ & 0.06 \\
\hline Vitamin D deficient & $-0.40(-0.70,-0.09)$ & 0.01 \\
\hline \multicolumn{3}{|l|}{$\mathrm{BMI}, \mathrm{kg} / \mathrm{m}^{2}$} \\
\hline$<25$ & reference & \\
\hline$\geq 25$ and $<30$ & $-0.09(-0.43,0.26)$ & 0.63 \\
\hline$\geq 30$ and $<35$ & $-0.45(-0.82,-0.09)$ & 0.02 \\
\hline$\geq 35$ & $-0.89(-1.27,-0.50)$ & $<0.001$ \\
\hline \multicolumn{3}{|l|}{ Income stratum in USD } \\
\hline$>100,000$ & reference & \\
\hline $50,001-100,000$ & $-0.44(-0.79,-0.09)$ & 0.01 \\
\hline $20,001-50,000$ & $-0.66(-1.05,-0.28)$ & 0.001 \\
\hline$<20,000$ & $-1.09(-1.56,-0.61)$ & $<0.001$ \\
\hline Declined response & $-0.57(-0.99,-0.15)$ & 0.008 \\
\hline \multicolumn{3}{|l|}{ Educational attainment } \\
\hline College graduate or higher & reference & \\
\hline Some college & $-0.09(-0.38,0.20)$ & 0.54 \\
\hline High school graduate & $-0.44(-0.83,-0.06)$ & 0.03 \\
\hline Less than high school & $-0.51(-1.02,0.01)$ & 0.06 \\
\hline
\end{tabular}

Anemia categorized as $<12 \mathrm{~g} / \mathrm{dl}$ for women and $<13 \mathrm{~g} / \mathrm{dl}$ for men. Vitamin D deficiency categorized as $<20 \mathrm{ng} / \mathrm{ml}$.

excluding BMI, diabetes was associated with a 0.42 -point lower SPPB score $(\mathrm{CI}-0.67,-0.16 ; \mathrm{p}=0.001)$. Tests for interaction between black race and age were not significant.

\section{Frailty}

Seventy-three individuals (7\%) were frail and 447 (43\%) were pre-frail. With reference to individual frailty criteria, $32 \%$ had weakness, $21 \%$ had exhaustion, $12 \%$ had low activity, $11 \%$ had slow walking, and $6 \%$ had unintentional weight loss over the past year.

The age-adjusted, predicted mean eGFR was 40 for frail, 44 for pre-frail and $54 \mathrm{ml} / \mathrm{min} / 1.73 \mathrm{~m}^{2}$ for non-frail participants. As in figure 2, worse renal function was associated with greater likelihood of worse frailty status. In multivariable ordinal logistic regression (table 3), eGFR 30-59 (OR 1.45; CI 1.05, 1.99; p = 0.024), eGFR 15-29 (OR 2.02; CI 1.29, 3.16; $\mathrm{p}=0.002)$ and eGFR $<15$ (OR $4.83 ; \mathrm{CI} 2.60,8.98 ; \mathrm{p}<0.001)$ were significantly associated with worse frailty status, compared with eGFR $>60 \mathrm{ml} /$ $\mathrm{min} / 1.73 \mathrm{~m}^{2}$. Age $\geq 65$ years, female sex, black race, BMI $\geq 35$, anemia, CVD and stroke were also associated with worse frailty status.

In multivariable logistic regression for the outcome of frailty alone (vs. pre-frail and non-frail), the eGFR categories of 30-59 (OR 1.49; CI 1.07, 2.06; p = 0.018), eGFR 15-29 (OR 2.21; CI 1.36, 3.58; $\mathrm{p}=0.001$ ) and eGFR $<15$ (OR 5.55; CI 2.48, 12.4; $\mathrm{p}<0.001$ ) were associated with an elevated odds of frailty.

Age-stratified ordinal logistic regression showed that black race was associated with worse frailty status among individuals $<65$ years (OR 1.95; CI 1.29, 2.96; $\mathrm{p}=0.002$ ), but not among those $\geq 65$ years (OR 1.17; CI 0.79, 1.74; $p=0.42$ ). In the ordinal logistic regression model with all participants, however, the black race by age $\geq 65$ years interaction did not reach significance (interaction OR 0.66; CI $0.39,1.12 ; \mathrm{p}=0.12$ ).

\section{Discussion}

This study is the first to examine both physical performance and frailty in a large, ethnically diverse cohort with a wide spectrum of CKD severity and age. Worse renal function demonstrated a graded association with worse physical performance and frailty, independent of age, sex, race, BMI, anemia, socioeconomic status and major comorbidities. These results underscore the need to define the fundamental biological mechanisms in kidney disease that drive the development of poor physical performance, frailty and loss of functional status. Additionally, CKD patients with worsening physical performance or prefrailty might benefit from targeted interventions to prevent further deterioration in global health.

The SPPB revealed clinically important variation in physical performance in the CRIC cohort. The only other non-transplant CKD population in which the SPPB has been measured is participants in the Frequent Hemodialysis Network (FHN) Trial. Among the 375 (mean age 51 years) FHN participants, $22 \%$ had SPPB scores $<7$ and $42 \%$ had scores $>10$ [32]. In our cohort, the proportions were 19 and 34\%, respectively, suggesting a similar burden of poor physical performance in the context of more 
Fig. 2. Prevalence of frailty and pre-frailty,

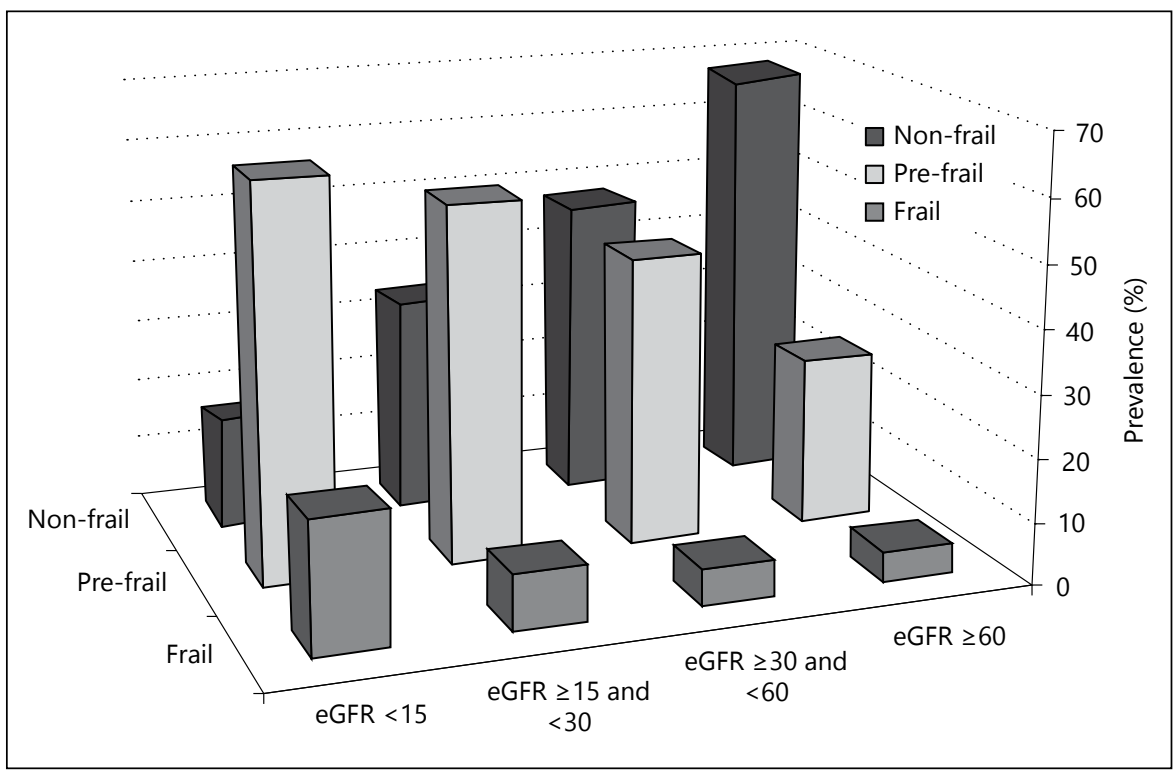
by category of eGFR.

Table 3. Ordinal logistic regression analysis of the categorical outcome of frailty/pre-frailty/non-frailty

\begin{tabular}{|c|c|c|c|c|c|c|}
\hline \multirow[t]{2}{*}{ Characteristics } & \multicolumn{3}{|c|}{ Univariate analysis } & \multicolumn{3}{|c|}{ Multivariable analysis } \\
\hline & OR & $95 \% \mathrm{CI}$ & $\mathrm{p}$ value & OR & $95 \% \mathrm{CI}$ & $\mathrm{p}$ value \\
\hline \multicolumn{7}{|l|}{$\mathrm{eGFR}$ in $\mathrm{ml} / \mathrm{min} / 1.73 \mathrm{~m}^{2}$} \\
\hline$>60$ & & reference & & & reference & \\
\hline $30-59$ & 2.26 & $1.69,3.04$ & $<0.001$ & 1.45 & $1.05,1.99$ & 0.024 \\
\hline $15-29$ & 3.88 & $2.58,5.83$ & $<0.001$ & 2.02 & $1.29,3.16$ & 0.002 \\
\hline$<15$ & 9.17 & $5.09,16.5$ & $<0.001$ & 4.83 & $2.60,8.98$ & $<0.001$ \\
\hline Age $\geq 65$ years & & & & 1.85 & $1.42,2.41$ & $<0.001$ \\
\hline Female & & & & 1.61 & $1.24,2.09$ & $<0.001$ \\
\hline Black race & & & & 1.50 & $1.13,1.98$ & 0.005 \\
\hline $\mathrm{BMI} \geq 35 \mathrm{~kg} / \mathrm{m}^{2}$ & & & & 1.69 & $1.23,2.31$ & 0.001 \\
\hline Cardiovascular disease & & & & 1.71 & $1.26,2.32$ & 0.001 \\
\hline Anemia & & & & 1.63 & $1.22,2.17$ & 0.001 \\
\hline Diabetes & & & & 1.24 & $0.94,1.63$ & 0.13 \\
\hline Stroke & & & & 2.08 & $1.33,3.24$ & 0.001 \\
\hline
\end{tabular}

Anemia categorized as $<12 \mathrm{~g} / \mathrm{dl}$ for women and $<13 \mathrm{~g} / \mathrm{dl}$ for men.

preserved renal function but older mean age (63 years) in CRIC.

Studies of the SPPB in community-dwelling elderly populations without known $\mathrm{CKD}$ have shown that 0.5 -point differences in SPPB are clinically meaningful, suggesting that the worse SPPB scores associated with severe renal dysfunction in our study would predict adverse health outcomes such as disability $[12,23,37]$. The modest correlation between SPPB score and the physical components score of the KDQOL supports the idea that ob- served physical performance and self-reported function capture related but distinct domains of physical health in CKD patients.

The prevalence of frailty (7\%) and pre-frailty (43\%) in CRIC paralleled those found in cohorts of communitydwelling people whose ages were much older. We measured frailty using criteria developed in the CHS, a cohort of elderly men and women (aged 65-101 years) in which the prevalence of frailty was $7 \%$ and pre-frailty was $47 \%$ [9]. These criteria were later validated in the Women's 
Health and Aging Studies (aged 70-79 years), which had a frailty prevalence of $11 \%$ [13]; this high prevalence was likely due, in part, to the inclusion of more severely disabled women through home visits. In another community-dwelling cohort aged 65-80 years, Espinoza and Hazuda [38] reported that $7 \%$ of individuals of European ancestry and $11 \%$ of individuals of Hispanic ancestry were frail. The similarity in the distribution of frailty status between our CKD cohort and cohorts of older community-dwelling people suggest an 'accelerated aging' associated with low GFR.

Our study also bears comparison to the recently reported results from the Seattle Kidney Study. The 336 CKD patients in the Seattle Kidney Study had a greater prevalence of frailty (14\%) and pre-frailty (52\%) than our cohort. Notably, the Seattle Kidney Study assessed weight loss using self-report and categorized low physical activity as self-reported exercise less than once a week [18]. In contrast, we determined weight loss using measured weights at study visits and categorized low physical activity using a systematic assessment of moderate to vigorous physical activities and applying gender-specific cutpoints for weekly energy expenditure that were defined by Fried et al. [9]. These differences in prevalence suggest that the identification of frailty depends to an important degree on the method of assessment [39]. However, despite these differences, our results confirm the graded association between eGFR and frailty that was reported in the Seattle study [18].

The biological mechanisms that cause poor physical performance and frailty in CKD are incompletely explained. Across the spectrum of renal dysfunction, CKD patients are more likely to have limited physical activity due to comorbidities such as CVD and anemia. Advanced $\mathrm{CKD}$ is often accompanied by inflammation and cachexia that promote loss of lean muscle mass and could worsen physical performance and promote frailty [7, 40, 41]. Further, CKD is associated with abnormalities in muscle function (particularly in proximal muscles), morphology and metabolism [42-45]. CKD patients also have elevated concentrations of inflammatory cytokines, including interleukin- 6 and tumor necrosis factor- $\alpha$, that are also associated with frailty [46]. Systemic inflammation, elevated angiotensin II levels and metabolic acidosis promote muscle catabolism through impaired insulin/insulin-like growth factor I intracellular signaling and the activation of caspase [6]. These pathologic processes could limit physical activity and worsen physical performance.

Black race was associated with a lower SPPB score and, among participants $<65$ years, with worse frailty status.

Physical Performance and Frailty in CKD
Notably, the SPPB analysis was also adjusted for vitamin $\mathrm{D}$, which has been proposed as a mediator in the association of race and kidney disease outcomes [47]. These associations of black race with poor physical performance and frailty in CKD confirm the results of other cohorts $[15,32]$. Interestingly, National Health and Nutrition Examination Survey data showed that black individuals $<65$ years with CKD had elevated mortality [35], while a competing risks analysis of dialysis patients revealed that black race was associated with a higher risk of death for patients $<50$ years but a survival advantage for patients $\geq 50$ years [36]. In summary, the elevated risk of death associated with CKD among black patients may depend on age. Our results also reveal the possibility that frailty status lies in the pathway of these relationships.

Future studies should examine the relationship of physical performance and frailty to end points including mortality and hospitalization in CKD. A study in sedentary elderly individuals randomized to either a comprehensive physical activity program (aerobic, strength, balance and flexibility exercises) versus a 'successful aging' program (education and light stretching) showed that the comprehensive physical activity led to greater improvement in SPPB scores (8.5 vs. 7.9; $\mathrm{p}<0.001)$ and prevented mobility disability (defined as inability to walk $400 \mathrm{~m}$ ), suggesting that similar interventions on CKD patients with poor SPPB scores or frailty could also improve health outcomes [48]. Moreover, a meta-analysis of exercise interventions in CKD concluded that benefits include improved quality of life as well as physical fitness, blood pressure and nutrition [43]. Our findings reinforce the need for targeted interventions in CKD that can drive improvements in global health measures such as frailty as well as hard outcomes such as death.

We acknowledge this study's limitations. The primary limitation is the cross-sectional design and the lack of data relating SPPB and frailty to clinical outcomes. Second, reported medical histories likely do not fully capture relevant comorbidities, potentially resulting in residual confounding. Third, we have neither cytokine levels at the time of the ancillary study visit to assess inflammation, nor measures of muscle mass. A fourth limitation is the use of eGFR rather than measured GFR. However, one would expect frailty to be associated with lower muscle mass, resulting in an overestimate of GFR, and likely biasing the association between eGFR and frailty to the null. Finally, $17 \%$ of eligible participants did not enroll in this ancillary study. Non-participants had worse renal function and evidence of worse physical function on the KDQOL questionnaire. It is unlikely, 
however, that the relationships between eGFR and physical performance or frailty differ in the participants versus non-participants.

\section{Conclusion}

Severity of renal dysfunction was strongly associated with frailty and worse physical performance in an ethnically diverse cohort of CKD patients. Additionally, female sex, black race, CVD, elevated BMI and lower socioeconomic status were identified as independent risk factors for poor physical function and frailty. These findings provide further evidence that frailty and physical performance lie in the pathway between CKD and adverse health outcomes [18]. Future studies should examine whether frailty and physical performance are useful independent predictors of survival, hospitalization, disability and other important end points in CKD. Lastly, measures of physical performance and frailty might identify CKD patients who would benefit from interventions involving physical therapy, nutrition or novel anti-inflammatory therapies.

\section{Acknowledgements}

This work was supported by NIH grants to the investigators: K23-DK078688-01 (Dr. Reese), K24-DK002651 (Dr. Feldman), K24-DK076808 (Dr. Leonard) and R01-DK064966 (Dr. Leonard).

Funding for the CRIC Study was obtained under a cooperative agreement from National Institute of Diabetes and Digestive and Kidney Diseases (U01DK060990, U01DK060984, U01DK061022, U01DK061021, U01DK061028, U01DK060980, U01DK060963, and U01DK060902). In addition, this work was supported in part by: the Perelman School of Medicine at the University of Pennsylvania Clinical and Translational Science Award NIH/NCATS UL1TR000003, Johns Hopkins University UL1 TR-000424, University of Maryland GCRC M01 RR-16500, Clinical and Translational Science Collaborative of Cleveland, UL1TR000439 from the National Center for Advancing Translational Sciences component of the National Institutes of Health and NIH roadmap for Medical Research, Michigan Institute for Clinical and Health Research UL1TR000433, University of Illinois at Chicago CTSA UL1RR029879, Tulane University Translational Research in Hypertension and Renal Biology P30GM103337, Kaiser NIH/NCRR UCSF-CTSI UL1 RR-024131.

\section{Disclosure Statement}

There are no conflicts of interest to report.

\section{References}

1 Go AS, Chertow GM, Fan D, McCulloch CE, Hsu CY: Chronic kidney disease and the risks of death, cardiovascular events, and hospitalization. N Engl J Med 2004;351: 1296-1305.

2 Plantinga LC, Johansen K, Crews DC, Shahinian VB, Robinson BM, Saran R, Burrows NR, Williams DE, Powe NR: Association of CKD with disability in the United States. Am J Kidney Dis 2011;57:212-227.

3 Fried LF, Lee JS, Shlipak M, Chertow GM, Green C, Ding J, Harris T, Newman AB: Chronic kidney disease and functional limitation in older people: health, aging and body composition study. J Am Geriatr Soc 2006;54: 750-756.

4 Shlipak MG, Fried LF, Crump C, Bleyer AJ, Manolio TA, Tracy RP, Furberg CD, Psaty BM: Elevations of inflammatory and procoagulant biomarkers in elderly persons with renal insufficiency. Circulation 2003;107:8792.

5 Garg AX, Blake PG, Clark WF, Clase CM, Haynes RB, Moist LM: Association between renal insufficiency and malnutrition in older adults: results from the NHANES III. Kidney Int 2001;60:1867-1874.

6 Workeneh BT, Mitch WE: Review of muscle wasting associated with chronic kidney disease. Am J Clin Nutr 2010;91:1128S-1132S.
7 Kalantar-Zadeh K, Ikizler TA, Block G, Avram MM, Kopple JD: Malnutrition-inflammation complex syndrome in dialysis patients: causes and consequences. Am J Kidney Dis 2003;42:864-881.

8 Hamerman D: Toward an understanding of frailty. Ann Intern Med 1999;130:945-950.

9 Fried LP, Tangen CM, Walston J, Newman AB, Hirsch C, Gottdiener J, Seeman T, Tracy R, Kop WJ, Burke G, McBurnie MA: Frailty in older adults: evidence for a phenotype. J Gerontol A Biol Sci Med Sci 2001;56:M146-M156.

10 Guralnik JM, Ferrucci L, Pieper CF, Leveille SG, Markides KS, Ostir GV, Studenski S, Berkman LF, Wallace RB: Lower extremity function and subsequent disability: consistency across studies, predictive models, and value of gait speed alone compared with the short physical performance battery. J Gerontol A Biol Sci Med Sci 2000;55:M221-M231.

11 Guralnik JM, Simonsick EM, Ferrucci L, Glynn RJ, Berkman LF, Blazer DG, Scherr PA, Wallace RB: A short physical performance battery assessing lower extremity function: association with self-reported disability and prediction of mortality and nursing home admission. J Gerontol 1994;49:M85-M94.

12 Guralnik JM, Ferrucci L, Simonsick EM, Salive ME, Wallace RB: Lower-extremity function in persons over the age of 70 years as a predictor of subsequent disability. $\mathrm{N}$ Engl J Med 1995;332:556-561.

13 Bandeen-Roche K, Xue QL, Ferrucci L, Walston J, Guralnik JM, Chaves P, Zeger SL, Fried LP: Phenotype of frailty: characterization in the women's health and aging studies. J Gerontol A Biol Sci Med Sci 2006;61:262-266.

14 Wilhelm-Leen ER, Hall YN, K Tamura M, Chertow GM: Frailty and chronic kidney disease: the third national health and nutrition evaluation survey. Am J Med 2009;122:664671

15 Shlipak MG, Stehman-Breen C, Fried LF, Song X, Siscovick D, Fried LP, Psaty BM, Newman AB: The presence of frailty in elderly persons with chronic renal insufficiency. Am J Kidney Dis 2004;43:861-867.

16 Johansen KL, Chertow GM, Jin C, Kutner NG: Significance of frailty among dialysis patients. J Am Soc Nephrol 2007;18:2960-2967.

17 Bao Y, Dalrymple L, Chertow GM, Kaysen GA, Johansen KL: Frailty, dialysis initiation, and mortality in end-stage renal disease. Arch Intern Med 2012;172:1071-1077.

18 Roshanravan B, Khatri M, Robinson-Cohen C, Levin G, Patel KV, de Boer IH, Seliger S, Ruzinski J, Himmelfarb J, Kestenbaum B: A prospective study of frailty in nephrology-referred patients with CKD. Am J Kidney Dis 2012;60:912-921. 
19 Feldman HI, Appel LJ, Chertow GM, Cifelli D, Cizman B, Daugirdas J, Fink JC, FranklinBecker ED, Go AS, Hamm LL, He J, Hostetter T, Hsu CY, Jamerson K, Joffe M, Kusek JW, Landis JR, Lash JP, Miller ER, Mohler ER 3rd, Muntner P, Ojo AO, Rahman M, Townsend RR, Wright JT: The Chronic Renal Insufficiency Cohort (CRIC) study: Design and methods. J Am Soc Nephrol 2003;14:S148S153.

20 Lash JP, Go AS, Appel LJ, He J, Ojo A, Rahman M, Townsend RR, Xie D, Cifelli D, Cohan J, Fink JC, Fischer MJ, Gadegbeku C, Hamm LL, Kusek JW, Landis JR, Narva A, Robinson N, Teal V, Feldman HI: Chronic Renal Insufficiency Cohort (CRIC) study: baseline characteristics and associations with kidney function. Clin J Am Soc Nephrol 2009; 4:1302-1311.

21 Fischer MJ, Go AS, Lora CM, Ackerson L, Cohan J, Kusek JW, Mercado A, Ojo A, Ricardo AC, Rosen LK, Tao K, Xie D, Feldman HI, Lash JP: CKD in Hispanics: baseline characteristics from the CRIC (Chronic Renal Insufficiency Cohort) and Hispanic-CRIC studies. Am J Kidney Dis 2011;58:214-227.

22 Anderson AH, Yang W, Hsu CY, Joffe MM, Leonard MB, Xie D, Chen J, Greene T, Jaar BG, Kao P, Kusek JW, Landis JR, Lash JP, Townsend RR, Weir MR, Feldman HI, CRIC Study Investigators: Estimating GFR among participants in the Chronic Renal Insufficiency Cohort (CRIC) study. Am J Kidney Dis 2012;60:250-261.

23 Perera S, Mody SH, Woodman RC, Studenski SA: Meaningful change and responsiveness in common physical performance measures in older adults. J Am Geriatr Soc 2006;54:743-749.

24 Ostir GV, Volpato S, Fried LP, Chaves P, Guralnik JM, Women's Health and Aging Study: Reliability and sensitivity to change assessed for a summary measure of lower body function: results from the Women's Health and Aging Study. J Clin Epidemiol 2002;55:916921.

25 Radloff L: The CES-D Scale: a self-report depression scale for research in the general population. Appl Psychol Meas 1977;1:385-401.

26 Bild DE, Bluemke DA, Burke GL, Detrano R, Diez Roux AV, Folsom AR, Greenland P, Jacob DR Jr, Kronmal R, Liu K, Nelson JC, O'Leary D, Saad MF, Shea S, Szklo M, Tracy RP: Multi-ethnic study of atherosclerosis: objectives and design. Am J Epidemiol 2002;156: 871-881.
27 Eckel SP, Bandeen-Roche K, Chaves PH, Fried LP, Louis TA: Surrogate screening models for the low physical activity criterion of frailty. Aging Clin Exp Res 2011;23:209-216.

28 Institute of Medicine: Dietary Reference Intakes for Calcium and Vitamin D. Washington, National Academies Press, 2010.

29 Hays RD, Kallich JD, Mapes DL, Coons SJ, Carter WB: Development of the Kidney Disease Quality of Life (KDQOL) instrument. Qual Life Res 1994;3:329-338.

30 Joffe M, Hsu CY, Feldman HI, Weir M, Landis JR, Hamm LL: Variability of creatinine measurements in clinical laboratories: results from the CRIC study. Am J Nephrol 2010;31: 426-434.

31 Kutner NG, Zhang R, Bowles T, Painter P: Pretransplant physical functioning and kidney patients' risk for posttransplantation hospitalization/death: evidence from a national cohort. Clin J Am Soc Nephrol 2006;1:837843.

32 Kaysen GA, Larive B, Painter P, Craig A, Lindsay RM, Rocco MV, Daugirdas JT, Schulman G, Chertow GM, Group FHNT: Baseline physical performance, health, and functioning of participants in the frequent hemodialysis network (FHN) trial. Am J Kidney Dis 2011;57:101-112.

33 Houston DK, Cesari M, Ferrucci L, Cherubini A, Maggio D, Bartali B, Johnson MA, Schwartz GG, Kritchevsky SB: Association between vitamin D status and physical performance: the InCHIANTI study. J Gerontol A Biol Sci Med Sci 2007;62:440-446.

34 Vittinghoff E, McCulloch CE: Relaxing the rule of ten events per variable in logistic and cox regression. Am J Epidemiol 2007;165: 710-718.

35 Mehrotra R, Kermah D, Fried L, Adler S, Norris K: Racial differences in mortality among those with CKD. J Am Soc Nephrol 2008;19: 1403-1410

36 Kucirka LM, Grams ME, Lessler J, Hall EC, James N, Massie AB, Montgomery RA, Segev DL: Association of race and age with survival among patients undergoing dialysis. JAMA 2011;306:620-626.

37 Volpato S, Cavalieri M, Sioulis F, Guerra G, Maraldi C, Zuliani G, Fellin R, Guralnik JM: Predictive value of the short physical performance battery following hospitalization in older patients. J Gerontol A Biol Sci Med Sci 2011;66:89-96.

38 Espinoza SE, Hazuda HP: Frailty in older Mexican-American and European-American adults: is there an ethnic disparity? J Am Geriatr Soc 2008; $56: 1744-1749$.
39 Saum KU, Muller H, Stegmaier C, Hauer K, Raum E, Brenner H: Development and evaluation of a modification of the fried frailty criteria using population-independent cutpoints. J Am Geriatr Soc 2012;60:2110-2115.

40 Fried LF, Boudreau R, Lee IS, Chertow G, Kurella-Tamura M, Shlipak MG, Ding J, Sellmeyer D, Tylavsky FA, Simsonick E, Kritchevsky SB, Harris TB, Newman AB, Health Aging and Body Composition Study: Kidney function as a predictor of loss of lean mass in older adults: Health, Aging and Body Composition Study. J Am Geriatr Soc 2007; 55:1578-1584.

41 Tonelli M, Sacks F, Pfeffer M, Jhangri GS, Curhan G, Cholesterol and Recurrent Events (CARE) Trial Investigators: Biomarkers of inflammation and progression of chronic kidney disease. Kidney Int 2005;68:237-245.

42 Kettner-Melsheimer A, Weiss M, Huber W: Physical work capacity in chronic renal disease. Int J Artif Organs 1987;10:23-30.

43 Heiwe S, Jacobson SH: Exercise training for adults with chronic kidney disease. Cochrane Database Syst Rev 2011;10:CD003236.

44 Heiwe S, Clyne N, Tollback A, Borg K: Effects of regular resistance training on muscle histopathology and morphometry in elderly patients with chronic kidney disease. Am J Phys Med Rehabil 2005;84:865-874.

45 Moore GE, Bertocci LA, Painter PL: 31pmagnetic resonance spectroscopy assessment of subnormal oxidative metabolism in skeletal muscle of renal failure patients. J Clin Invest 1993;91:420-424.

46 Keller C, Katz R, Cushman M, Fried LF, Shlipak M: Association of kidney function with inflammatory and procoagulant markers in a diverse cohort: a cross-sectional analysis from the multi-ethnic study of atherosclerosis (MESA). BMC Nephrol 2008;9:9.

47 Melamed ML, Astor B, Michos ED, Hostetter TH, Powe NR, Muntner P: 25-hydroxyvitamin $\mathrm{D}$ levels, race, and the progression of kidney disease. J Am Soc Nephrol 2009;20:2631-2639.

48 LIFE Study Investigators, Pahor M, Blair SN Espeland M, Fielding R, Gill TM, Guralnik JM, Hadley EC, King AC, Kritchevsky SB, Maraldi C, Miller ME, Newman AB, Rejeski WJ, Romashkan S, Studenski S: Effects of a physical activity intervention on measures of physical performance: results of the lifestyle interventions and independence for elders pilot (LIFE-P) study. J Gerontol A Biol Sci Med Sci 2006;61:1157-1165. 